\title{
Study for Initial Load Effects on the Calibration of Load Cells
}

\author{
Seifelnasr M. Osman ${ }^{1, *}$, R. Hegazy ${ }^{2}$, M. A. Elhakeem ${ }^{3}$, and M. I. Mohamad ${ }^{4}$ \\ ${ }^{1}$ National Institute of Standards (NIS) \\ Tersa St. ElHaram (Giza, Egypt) \\ Email: Seifelnasr_nis [AT] yahoo.com \\ ${ }^{2}$ National Institute of Standards (NIS) \\ Tersa St. ElHaram (Giza, Egypt) \\ Email: rihamhegazy [AT] yahoo.com \\ ${ }^{3}$ National Institute of Standards (NIS) \\ Tersa St. ElHaram (Giza, Egypt) \\ Email: moh_mech2007 [AT] yahoo.com \\ ${ }^{4}$ National Institute of Standards (NIS) \\ Tersa St. ElHaram (Giza, Egypt) \\ Email: magdi_i_m [AT] yahoo.com \\ *Corresponding author: Seif M. Osman
}

\begin{abstract}
This work was carried out by the National Institute of Standards NIS), Egypt, as a result of experimental cases in load cell applications. The aim of this study is to compare the behavior of load cell works under initial load with the ideal working case. The study was carried out using seven load cells from different manufacturers and with different types, capacities, working modes and classes. As a result of the behavior of the load cells during this study; it is clear that the response of the load cells previously loaded against applied load differ from the ideal case. Load cell operators have to carry out mathematical calculations to correct the reading rather than using electrical methods to readjust the zero signal and neglecting the initial applied load.
\end{abstract}

Keywords— Load cell, initial load, strain gauges, calibration, loading frame.

\section{INTRODUCTION}

Load cell is a force transducer based on using a strain gauge bond to an elastic element which has to deform elastically under loads[1], in order to give an expected pre-determined response to indicate the applied true load. According to the international standards (ASTM E74[2] \& ISO 376[3]) load cells are from zero output (no load case), but in some real applications load cells are initially loaded due to the design feature or nature of the application. In some applications there is a need to apply an initial load on the load cell before start measurements; one of these applications is using a load cell as a reference standard in carrying out secondary force calibrations using the universal loading frame (see fig. 1) [4]. Universal loading frame with a reference standard load cell - calibrated on a deadweight machine which realizes SI units- can be considered as a secondary standard in force measurements traceability chain.

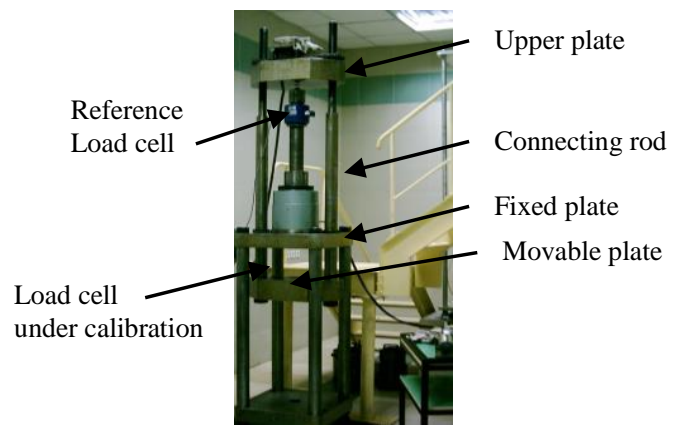

Figure 1: NIS universal loading frame

In the universal loading frame; the reference load cell has to be placed between the upper and the fixed plate while the load cell under calibration has to be placed in between the movable and the fixed plates. Thus, the upper plate, the 
movable plate and their connecting rods have to be loaded on the reference load cell before apply calibration loads. The weight of these objects has to be considered as an initial load on the load cell

(which may reflect on its response under calibration loads, another application is some bridges like the BurlingtonBristol Bridge,

In the spring of 2010, the expansion bearings of the Burlington-Bristol Bridge were replaced due to a poor condition rating that caused the bridge to be classified as structurally deficient). The replacement of these bearings represented a unique opportunity to configure the new bearings to monitor the dead load and live load actions as well as their variation with environmental conditions. In these cases; the elastic element of the load cell is already has percentage of deformation directly proportional to the applied load according to the elastic theories [5]. As a result; the range of calibration of the load cells differs from the working range because the calibration conditions differ from the working conditions.

\section{STUDY PLAN}

During the study seven different load cells from different manufacturers and with different types, capacities, working modes and classes were used. Each load cell was calibrated four times according to the international standard ISO/IEC 376 up to $100 \%$ of its capacity. The following table (Table (1)) summaries the study plan.

Table 1: Study schemes

\begin{tabular}{c|c|c}
\hline Calibration scheme & Applied static load & Calibration points \\
\hline First $\left(1^{\text {st }}\right)$ & No static load & 10 \\
Second (2nd & $10 \%$ of Capacity & 9 \\
Third $\left(3^{\text {rd }}\right)$ & $20 \%$ of Capacity & 8 \\
Fourth $\left(4^{\text {th }}\right)$ & $50 \%$ of Capacity & 5 \\
\hline
\end{tabular}

First calibration scheme is the standard calibration procedure. Second, third and fourth calibration schemes were carried out after applying a static load - on the load cell- according to Table (1). The load cell output was readjusted to zero signals before carrying out calibrations according to $2 \mathrm{nd}$, 3rd and 4th calibration schemes.

\section{MEASUREMENTS}

Measurements were carried out using NIS $50 \mathrm{kN} \& 500 \mathrm{kN}$ Deadweight machines (see figure (1)). The responses of the load cells under calibration load $(\mathrm{kN})$ were monitored using DMP-40 (mV/V) manufactured by HBM Company [5] to get trustable data. Taken into considerations not to apply the load cell nominal capacity on the load cell which is already loaded by a static load (in case of the 2 nd, 3 rd \& 4 th calibrations) to avoid overloading process.

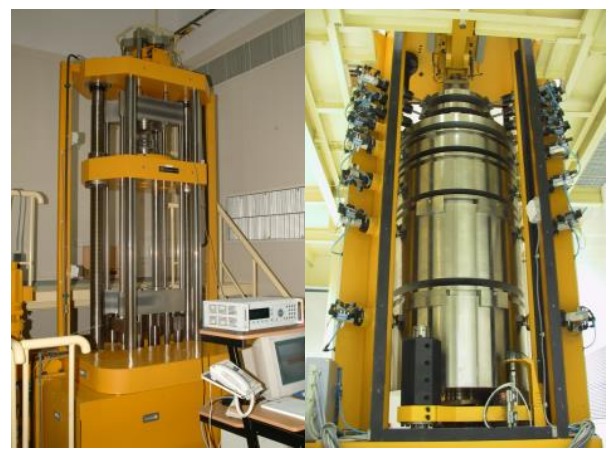

Figure 2: NIS500 kN DWM \& NIS $50 \mathrm{kN}$ DWM respectively

\section{RESULTS AND DISCUSSION}

Measurements were carried out on seven different load cells. The following table (Table (2)) shows the coefficients of the a 3 rd degree fitting equation (equation 1) resulted from curve fitting of the calibration data

Force $=\mathrm{A} x$ Deflection $+\mathrm{B} \times$ Deflrction $^{2}+$ Force $^{\mathrm{x}}$ Deflrction $^{3}$ 
Table 2: Coefficient of a $3^{\text {rd }}$ degree calibration equation

\begin{tabular}{|c|c|c|c|c|}
\hline \multirow{2}{*}{$\begin{array}{c}\text { Load cell } \\
\text { Identification }\end{array}$} & \multirow{2}{*}{$\begin{array}{l}\text { Calibration } \\
\text { Scheme }\end{array}$} & \multicolumn{3}{|c|}{$\begin{array}{c}\text { Coefficients of a } 3^{\text {rd }} \text { degree fitting equation } \\
\text { (equation 1) }\end{array}$} \\
\hline & & A & B & C \\
\hline \multirow{4}{*}{$\begin{array}{l}\text { Load Cell } 1 \\
\qquad(20 \mathrm{kN})\end{array}$} & $1^{\text {st }}$ & 7.370429 & -0.009069 & 0.002176 \\
\hline & $2^{\text {nd }}$ & 7.362052 & -0.003825 & 0.001328 \\
\hline & $3^{\text {rd }}$ & 7.360948 & -0.003465 & 0.001533 \\
\hline & $4^{\text {th }}$ & 7.361162 & -0.005715 & 0.004519 \\
\hline \multirow{4}{*}{$\begin{array}{l}\text { Load Cell } 2 \\
(20 \mathrm{kN})\end{array}$} & $1^{\text {st }}$ & 7.373493 & -0.008433 & 0.001677 \\
\hline & $2^{\text {nd }}$ & 7.363901 & -0.002314 & 0.000516 \\
\hline & $3^{\text {rd }}$ & 7.363812 & -0.002993 & 0.000825 \\
\hline & $4^{\text {th }}$ & 7.363786 & -0.007438 & 0.003970 \\
\hline \multirow{4}{*}{$\begin{array}{l}\text { Load Cell } 3 \\
\quad(450 \mathrm{kN})\end{array}$} & $1^{\text {st }}$ & 221.669883 & -0.023151 & 0.056362 \\
\hline & $2^{\text {nd }}$ & 221.421979 & 0.304828 & -0.040313 \\
\hline & $3^{\text {rd }}$ & 221.518748 & 0.309955 & -0.051282 \\
\hline & $4^{\text {th }}$ & 221.862484 & 0.159565 & -0.015800 \\
\hline \multirow{4}{*}{$\begin{array}{l}\text { Load Cell } 4 \\
(450 \mathrm{kN})\end{array}$} & $1^{\text {st }}$ & 221.206486 & 0.208403 & -0.000329 \\
\hline & $2^{\text {nd }}$ & 221.181073 & 0.340835 & -0.044118 \\
\hline & $3^{\text {rd }}$ & 221.275287 & 0.365046 & -0.062774 \\
\hline & $4^{\text {th }}$ & 221.651840 & 0.221934 & -0.037464 \\
\hline \multirow{4}{*}{$\begin{array}{l}\text { Load Cell } 5 \\
\qquad(5 \mathrm{kN})\end{array}$} & $1^{\text {st }}$ & 2.497390 & -0.000649 & 0.000256 \\
\hline & $2^{\text {nd }}$ & 2.502559 & -0.006867 & 0.002353 \\
\hline & $3^{\text {rd }}$ & 2.496741 & -0.000858 & 0.000626 \\
\hline & $4^{\text {th }}$ & 2.496764 & -0.000886 & 0.001428 \\
\hline \multirow{4}{*}{$\begin{array}{l}\text { Load Cell } 6 \\
\qquad(10 \mathrm{kN})\end{array}$} & $1^{\text {st }}$ & 4.993285 & -0.002514 & 0.001464 \\
\hline & $2^{\text {nd }}$ & 4.991371 & -0.000332 & 0.001031 \\
\hline & $3^{\text {rd }}$ & 4.991489 & 0.000117 & 0.001095 \\
\hline & $4^{\text {th }}$ & 4.992491 & 0.002771 & 0.000701 \\
\hline \multirow{4}{*}{$\begin{array}{l}\text { Load Cell } 7 \\
\qquad(5 \mathrm{kN})\end{array}$} & $1^{\text {st }}$ & 2.499918 & -0.001274 & 0.000070 \\
\hline & $2^{\text {nd }}$ & 2.499568 & -0.001397 & 0.000123 \\
\hline & $3^{\text {rd }}$ & 2.498635 & -0.000796 & -0.000074 \\
\hline & $4^{\text {th }}$ & 2.498236 & -0.002558 & 0.000970 \\
\hline
\end{tabular}

The actual resulted data resulted from the four calibration schemes were compared to each other for the same calibration load. Tables (3), (4) and (5) show the relative error between the 2nd, 3rd, and 4th scheme respectively with respect to the 1st (standard) calibration scheme. It is clear form the results of the relative error calculations that each load cell has a unique trend when calibrated under initial static load, however the relative error decreases as the calibration load increase

Table 3: The percentage error between $1^{\text {st }}$ and $2^{\text {nd }}$ calibration results

\begin{tabular}{|c|c|c|c|c|c|c|c|c|c|}
\hline \multirow{2}{*}{$\begin{array}{c}\text { Load cell } \\
\text { Identification }\end{array}$} & \multicolumn{9}{|c|}{ Relative Error between $1^{\text {st }} \& 2^{\text {nd }}$ calibration scheme results } \\
\hline & $10 \%$ & $20 \%$ & $30 \%$ & $40 \%$ & $50 \%$ & $60 \%$ & $70 \%$ & $80 \%$ & $90 \%$ \\
\hline Load Cell 1 (20kN) & 0.153 & 0.081 & 0.060 & 0.045 & 0.035 & 0.027 & 0.022 & 0.020 & 0.004 \\
\hline Load Cell 2 (20 kN) & 0.189 & 0.093 & 0.066 & 0.054 & 0.039 & 0.040 & 0.028 & 0.033 & 0.017 \\
\hline Load Cell $3(450 \mathrm{kN})$ & 0.178 & 0.071 & 0.030 & 0.012 & -0.001 & -0.003 & -0.008 & -0.010 & -0.010 \\
\hline Load Cell $4(450 \mathrm{kN})$ & 0.030 & 0.005 & -0.023 & -0.030 & -0.031 & -0.034 & -0.032 & -0.031 & -0.031 \\
\hline Load Cell 5 (5 kN) & -0.481 & -0.092 & -0.060 & -0.045 & -0.038 & -0.031 & -0.029 & -0.029 & -0.030 \\
\hline Load Cell 6 (10 kN) & 0.052 & 0.022 & 0.015 & 0.005 & 0.003 & -0.002 & -0.004 & -0.010 & -0.011 \\
\hline Load Cell 7 (5 kN) & -0.005 & 0.021 & 0.017 & 0.019 & 0.014 & 0.017 & 0.017 & 0.018 & 0.015 \\
\hline
\end{tabular}


Table 4: The percentage error between $1^{\text {st }}$ and $3^{\text {rd }}$ calibration results

\begin{tabular}{c|c|c|c|c|c|c|c|c}
\hline $\begin{array}{c}\text { Load cell } \\
\text { Identification }\end{array}$ & \multicolumn{6}{|c}{ Relative Error between 1 } \\
& $\mathbf{1 0 \%}$ & $\mathbf{2 0 \%}$ & $\mathbf{3 0 \%}$ & $\mathbf{4 0 \%}$ & $\mathbf{5 0 \%}$ & $\mathbf{6 0 \%}$ & $\mathbf{7 0 \%}$ & $\mathbf{8 0 \%}$ \\
\hline Load Cell 1 (20kN) & 0.163 & 0.095 & 0.069 & 0.050 & 0.037 & 0.027 & 0.023 & 0.005 \\
Load Cell 2 (20 kN) & 0.186 & 0.098 & 0.075 & 0.056 & 0.049 & 0.041 & 0.039 & 0.028 \\
Load Cell 3 (450 kN) & 0.143 & 0.027 & -0.013 & -0.033 & -0.040 & -0.042 & -0.045 & -0.044 \\
Load Cell 4 (450 kN) & 0.010 & -0.044 & -0.072 & -0.075 & -0.077 & -0.075 & -0.072 & -0.070 \\
Load Cell 5 (5 kN) & -0.183 & 0.060 & 0.040 & 0.028 & 0.021 & 0.016 & 0.007 & -0.002 \\
Load Cell 6 (10 kN) & 0.044 & 0.019 & 0.005 & -0.004 & -0.010 & -0.016 & -0.023 & -0.029 \\
Load Cell 7 (5 kN) & 0.042 & 0.049 & 0.044 & 0.038 & 0.035 & 0.037 & 0.038 & 0.035 \\
\hline
\end{tabular}

Table 5: The percentage error between $1^{\text {st }}$ and $4^{\text {th }}$ calibration results

\begin{tabular}{c|c|c|c|c|c}
\hline $\begin{array}{c}\text { Load cell } \\
\text { Identification }\end{array}$ & \multicolumn{4}{|c}{ Relative Error between 1 } & \multicolumn{3}{c}{ results } & $4^{\text {th }}$ & calibration scheme \\
& $\mathbf{1 0 \%}$ & $\mathbf{2 0 \%}$ & $\mathbf{3 0 \%}$ & $\mathbf{4 0 \%}$ & $\mathbf{5 0 \%}$ \\
\hline Load Cell 1 (20kN) & 0.173 & 0.092 & 0.058 & 0.038 & 0.002 \\
Load Cell 2 (20 kN) & 0.197 & 0.123 & 0.085 & 0.080 & 0.051 \\
Load Cell 3 (450 kN) & -0.005 & -0.101 & -0.133 & -0.143 & -0.143 \\
Load Cell 4 (450 kN) & -0.152 & -0.192 & -0.205 & -0.199 & -0.192 \\
Load Cell 5 (5 kN) & -0.189 & 0.052 & 0.029 & 0.009 & -0.010 \\
Load Cell 6 (10 kN) & 0.016 & -0.025 & -0.041 & -0.063 & -0.075 \\
Load Cell 7 (5 kN) & 0.070 & 0.088 & 0.084 & 0.086 & 0.081 \\
\hline
\end{tabular}

The following table (Table (6)) shows the response values calculated from the 3rd degree fitting equation (Table (2)) at $10 \%, 20 \% 30 \%$ and $50 \%$ of each load cell nominal capacity. In this table the force (as a percentage of the nominal capacity) is used and corrected according to the fitting equation (equation 1) resulted from the four calibration schemes used in this study.

Table 6: Force values after correcting using $3^{\text {rd }}$ degree fitting equations

\begin{tabular}{|c|c|c|c|c|c|c|}
\hline \multirow{2}{*}{$\begin{array}{c}\text { Load cell } \\
\text { Identification }\end{array}$} & \multirow{2}{*}{$\begin{array}{c}\% \\
\text { Nominal } \\
\text { capacity }\end{array}$} & \multirow{2}{*}{$\begin{array}{c}\text { Nominal } \\
\text { Force } \\
(\mathbf{k N})\end{array}$} & \multicolumn{4}{|c|}{$\begin{array}{l}\text { Calculated force }(\mathrm{kN}) \text { after correcting the nominal } \\
\text { force using the } 3^{\text {rd }} \text { degree fitting equation (1) }\end{array}$} \\
\hline & & & Normal & $10 \%$ & $20 \%$ & $50 \%$ \\
\hline \multirow{4}{*}{$\begin{array}{l}\text { Load Cell } 1 \\
\qquad(20 \mathrm{kN})\end{array}$} & $10 \%$ & 2.0 & 1.997735 & 2.000783 & 2.000989 & 2.001188 \\
\hline & $20 \%$ & 4.0 & 3.998518 & 4.001772 & 4.002310 & 4.002192 \\
\hline & $30 \%$ & 6.0 & 5.999507 & 6.003093 & 6.003645 & 6.002983 \\
\hline & $50 \%$ & 10.0 & 10.002163 & 10.005617 & 10.005837 & 10.002340 \\
\hline \multirow{4}{*}{$\begin{array}{l}\text { Load Cell } 2 \\
(20 \mathrm{kN})\end{array}$} & $10 \%$ & 2.0 & 1.997358 & 2.001137 & 2.001071 & 2.001292 \\
\hline & $20 \%$ & 4.0 & 3.998496 & 4.002208 & 4.002407 & 4.003402 \\
\hline & $30 \%$ & 6.0 & 5.999567 & 6.003545 & 6.004082 & 6.004679 \\
\hline & $50 \%$ & 10.0 & 10.002578 & 10.006512 & 10.007484 & 10.007676 \\
\hline \multirow{4}{*}{$\begin{array}{l}\text { Load Cell } 3 \\
\qquad(450 \mathrm{kN})\end{array}$} & $10 \%$ & 45.0 & 44.961387 & 45.041201 & 45.025681 & 44.959170 \\
\hline & $20 \%$ & 90.0 & 90.002588 & 90.066882 & 90.026975 & 89.911690 \\
\hline & $30 \%$ & 135.0 & 135.028269 & 135.068176 & 135.010533 & 134.848690 \\
\hline & $50 \%$ & 225.0 & 225.013121 & 225.010904 & 224.922223 & 224.691651 \\
\hline \multirow{3}{*}{$\begin{array}{l}\text { Load Cell } 4 \\
(450 \mathrm{kN})\end{array}$} & $10 \%$ & 45.0 & 45.013580 & 45.026865 & 45.018008 & 44.944942 \\
\hline & $20 \%$ & 90.0 & 90.040445 & 90.044873 & 90.000590 & 89.867742 \\
\hline & $30 \%$ & 135.0 & 135.058453 & 135.027455 & 134.961031 & 134.781685 \\
\hline
\end{tabular}




\begin{tabular}{|c|c|c|c|c|c|c|}
\hline \multirow{3}{*}{$\begin{array}{l}\text { Load cell } \\
\text { Identification }\end{array}$} & \multirow{2}{*}{$\begin{array}{c}\% \\
\text { Nominal } \\
\text { capacity }\end{array}$} & \multirow{2}{*}{$\begin{array}{c}\text { Nominal } \\
\text { Force } \\
(\mathbf{k N})\end{array}$} & \multicolumn{4}{|c|}{$\begin{array}{l}\text { Calculated force }(\mathrm{kN}) \text { after correcting the nominal } \\
\text { force using the } 3^{\text {rd }} \text { degree fitting equation (1) }\end{array}$} \\
\hline & & & Normal & $10 \%$ & $20 \%$ & $50 \%$ \\
\hline & $50 \%$ & 225.0 & 225.001476 & 224.932837 & 224.828772 & 224.569717 \\
\hline \multirow{4}{*}{$\begin{array}{l}\text { Load Cell } 5 \\
\qquad(5 \mathrm{kN})\end{array}$} & $10 \%$ & 0.5 & 0.501018 & 0.498605 & 0.500099 & 0.500069 \\
\hline & $20 \%$ & 1.0 & 0.999623 & 0.998704 & 1.000220 & 1.000142 \\
\hline & $30 \%$ & 1.5 & 1.499722 & 1.498825 & 1.500328 & 1.500159 \\
\hline & $50 \%$ & 2.5 & 2.499951 & 2.499002 & 2.500471 & 2.499692 \\
\hline \multirow{4}{*}{$\begin{array}{l}\text { Load Cell } 6 \\
\qquad(10 \mathrm{kN})\end{array}$} & $10 \%$ & 1.0 & 0.999675 & 1.000199 & 1.000117 & 0.999837 \\
\hline & $20 \%$ & 2.0 & 1.999874 & 2.000316 & 2.000249 & 1.999370 \\
\hline & $30 \%$ & 3.0 & 2.999991 & 3.000448 & 3.000133 & 2.998758 \\
\hline & $50 \%$ & 5.0 & 5.000008 & 5.000170 & 4.999503 & 4.996276 \\
\hline \multirow{4}{*}{$\begin{array}{l}\text { Load Cell } 7 \\
\qquad(5 \mathrm{kN})\end{array}$} & $10 \%$ & 0.5 & 0.499845 & 0.499820 & 0.500058 & 0.500198 \\
\hline & $20 \%$ & 1.0 & 0.999666 & 0.999878 & 1.000158 & 1.000543 \\
\hline & $30 \%$ & 1.5 & 1.499723 & 1.499978 & 1.500386 & 1.500980 \\
\hline & $50 \%$ & 2.5 & 2.500051 & 2.500404 & 2.500928 & 2.502065 \\
\hline
\end{tabular}

From the previous table (Table (6)) it is clear that substituting by the same nominal force in the four fitting equations leads to different values, which indicate that using a fitting equation resulted from an standard calibration scheme to predict an additional load on load cell initially loaded will result in a different response.

The following Figures (Fig. 3 - 9) plot the deviations between the Standard calibration scheme $\left(1^{\text {st }}\right)$ and the other calibration schemes $\left(2^{\text {nd }}, 3^{\text {rd }} \& 4^{\text {th }}\right)$. It is clear that each load cell has different behavior when works under initial load but for a specific load cell, the deviation between the 1 st calibration scheme and the other calibration schemes $\left(2^{\text {nd }}, 3^{\text {rd }} \& 4^{\text {th }}\right)$ have the same trend.

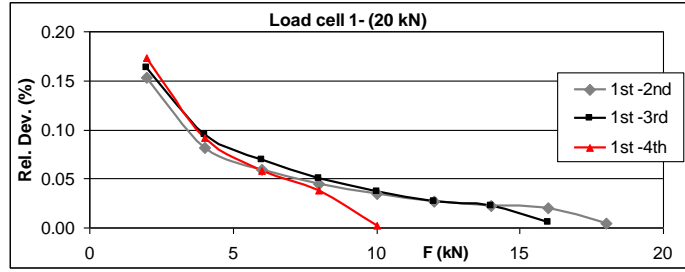

Figure 3: Deviation between the $1^{\text {st }}$ calibration scheme and the other calibration schemes $\left(2^{\text {nd }}, 3^{\text {rd }} \& 4^{\text {th }}\right)$; L.C: $20 \mathrm{kN}-\mathrm{A}$

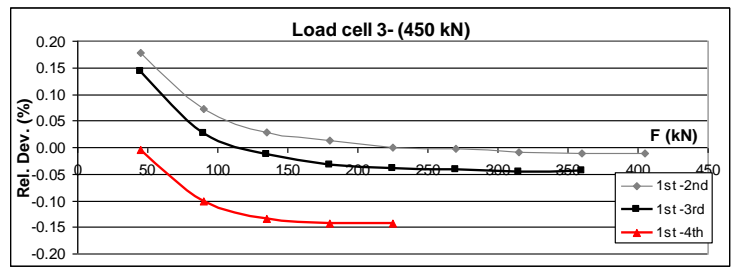

Figure 5: Deviation between the $1^{\text {st }}$ calibration scheme and the other calibration schemes $\left(2^{\text {nd }}, 3^{\text {rd }} \& 4^{\text {th }}\right)$; L.C: 450 $\mathrm{kN}-\mathrm{B}$

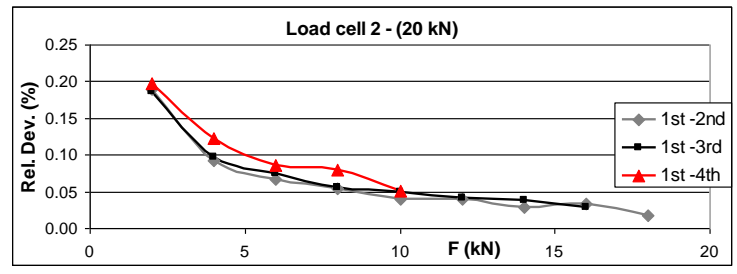

Figure 4: Deviation between the 1st calibration scheme and the other calibration schemes $\left(2^{\text {nd }}, 3^{\text {rd }} \& 4^{\text {th }}\right)$; L.C: 20 $\mathrm{kN}-\mathrm{B}$

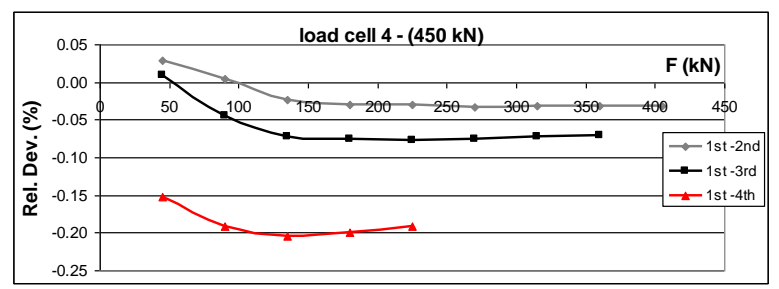

Figure 6: Deviation between the $1^{\text {st }}$ calibration scheme and the other calibration schemes $\left(2^{\text {nd }}, 3^{\text {rd }} \& 4^{\text {th }}\right)$; L.C: 450 $\mathrm{kN}-\mathrm{A}$ 


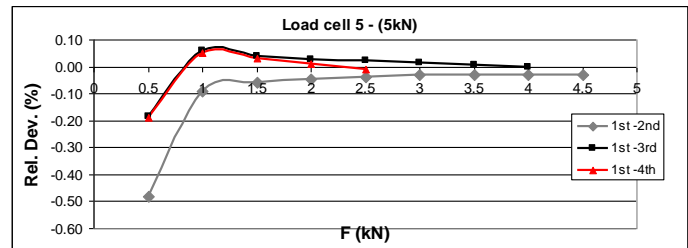

Figure 7: Deviation between the $1^{\text {st }}$ calibration scheme and the other calibration schemes $\left(2^{\text {nd }}, 3^{\text {rd }} \& 4^{\text {th }}\right)$; L.C: 5 $\mathrm{kN}-\mathrm{A}$

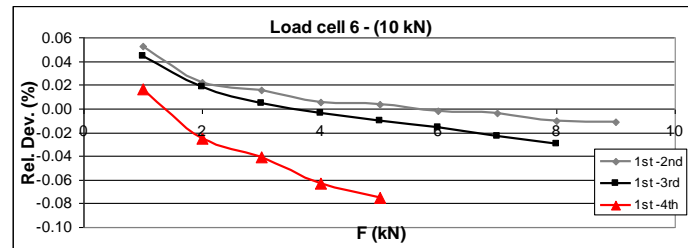

Figure 8: Deviation between the $1^{\text {st }}$ calibration scheme and the other calibration schemes $\left(2^{\text {nd }}, 3^{\text {rd }} \& 4^{\text {th }}\right)$; L.C: 10 $\mathrm{kN}$

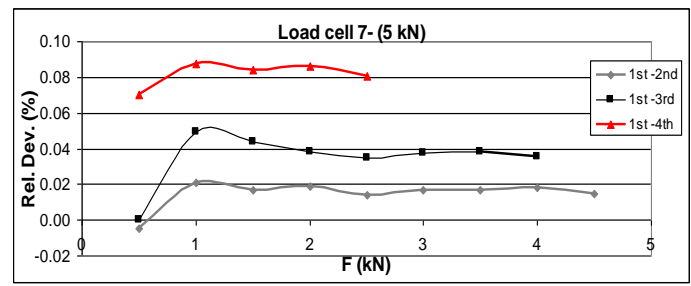

Figure 9: Deviation between the $1^{\text {st }}$ calibration scheme and the other calibration schemes $\left(2^{\text {nd }}, 3^{\text {rd }} \& 4^{\text {th }}\right)$; L.C: 5 kN-B

As a result of the behavior of the load cells during this study; it is clear that the response of the load cells previously loaded against applied load differ from the ideal case. The initially loaded load cell response will be a result from different stage in the response curve. Figure (10) is a virtual response of a $100 \mathrm{kN}$ load cell which is used to demonstrate the case study. Figure (10.A) shows a normal response of the load cell from $10-100 \%$ of its capacity, if the $100 \mathrm{kN}$ load cell is initially loaded by $20 \%(20 \mathrm{kN})$ then the left hand side (Figure $10 . \mathrm{B}$ ) will be neglected and the load cell will react to further applied loads according to the right hand side (Figure 10.C). Figure (10.D) is the response curve of $100 \mathrm{kN}$ load cell after being initially loaded by $20 \%(20 \mathrm{kN})$ which is differ from the standard response curve (Figurer 10.A).
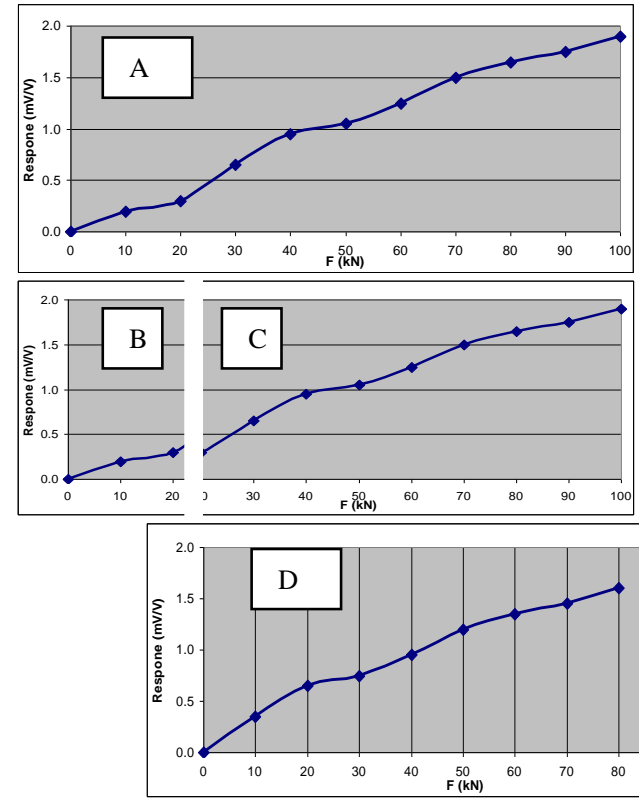

Figure 10: Virtual $100 \mathrm{kN}$ L.C. without \& with $20 \%$ initial load

\section{STATISTICAL ANALYSIS}

To study the previously mentioned results of the Standard calibration scheme (1st) and the other calibration schemes (2nd, 3rd\& 4th), Preliminary approach [7] normal distribution was used for comparison of the results of the two methods.

If $\mathrm{x}$, and $\mathrm{y}$ are standard and other calibration schemes respectively, and normally distributed values, then the following equations can be applied. 


$$
\begin{aligned}
& \bar{x}=\sum_{i=1}^{n} \frac{x i}{n} \\
& \bar{y}=\sum_{i=1}^{n} \frac{y i}{n} \\
& t_{2}=\frac{(\bar{x}-\bar{y})}{\sqrt{\frac{(n x-1) s^{2}{ }_{x}+(n y-1) s_{y}{ }^{2}}{n_{x}+n_{y}-2} \sqrt{\frac{1}{n_{y}}+\frac{1}{n_{x}}}}}
\end{aligned}
$$

\section{Where:}

Sx, and Sy are the standard deviations of the results of the standard, and developed method respectively.

$$
\mathrm{nx}=3 \quad \mathrm{n}_{\mathrm{y}}=3
$$

$v=n x+n y-2=4$

For $95 \%$ confidence level $1-\alpha=0.95, \alpha / 2=0.025$

t0.025:4 from $\mathrm{t}$ - distribution tables $=2.776$

since, $t_{2}>t \alpha / 2$ for most of calibration steps ,so the three calibration schemes is significantly different from the standard method.

Table (7) summarizes the results of the preliminary approach comparison method, for all calibration schemes,

It is concluded from the experimental work that; using a force transducer (load cell) loaded with initial load gives different response values from that if the load cell has no initial load.

Universal loading frames and reference standard load cell as a force secondary standards face the initial load case (static load) presented through this study and this may affect their calibration results.

Load cell operators have to carry out mathematical calculations to correct the reading rather than using electrical

\begin{tabular}{|c|c|c|c|c|c|c|c|c|c|}
\hline \multirow{2}{*}{$\begin{array}{l}\text { Load cell } \\
\text { Identification }\end{array}$} & \multirow{2}{*}{$\begin{array}{l}\% \text { Nominal } \\
\text { capacity }\end{array}$} & \multirow{2}{*}{$\begin{array}{c}\text { Nominal } \\
\text { Force }(\mathrm{kN})\end{array}$} & Standard & \multicolumn{3}{|c|}{ Sy } & \multicolumn{3}{|c|}{$t_{2}$} \\
\hline & & & $\mathrm{Sx}$ & $10 \%$ & $20 \%$ & $50 \%$ & $10 \%$ & $20 \%$ & $50 \%$ \\
\hline \multirow{2}{*}{$\begin{array}{l}\text { Load Cell } 1 \\
(20 \mathrm{kN})\end{array}$} & $20 \%$ & 4 & 0.0003 & 0.0005 & 0.0006 & 0.0007 & -4.83291 & -4.89545 & -4.54539 \\
\hline & $30 \%$ & 6 & 0.00049 & 0.0006 & 0.0005 & 0.001 & -4.00894 & -5.11893 & -3.01030 \\
\hline \multirow{3}{*}{$\begin{array}{l}\text { Load Cell } 2 \\
(20 \mathrm{kN})\end{array}$} & $20 \%$ & 4 & 0.0003 & $\begin{array}{r}0.0004 \\
1\end{array}$ & 0.0005 & 0.0008 & -6.32768 & -5.8087 & -5.31090 \\
\hline & $30 \%$ & 6 & 0.0006 & 0.0007 & 0.0008 & 0.0007 & -3.73668 & -3.9101 & -6.32445 \\
\hline & $50 \%$ & 10 & 0.0007 & 0.0008 & 0.0009 & 0.001 & -3.20498 & -3.72637 & -4.41499 \\
\hline
\end{tabular}
methods to readjust the zero signals and neglecting the initial applied load. Elsewhere, a new source of uncertainty shall be estimated and depends on the percentage of the applied load

Table 7 result of Preliminary approach comparison method 


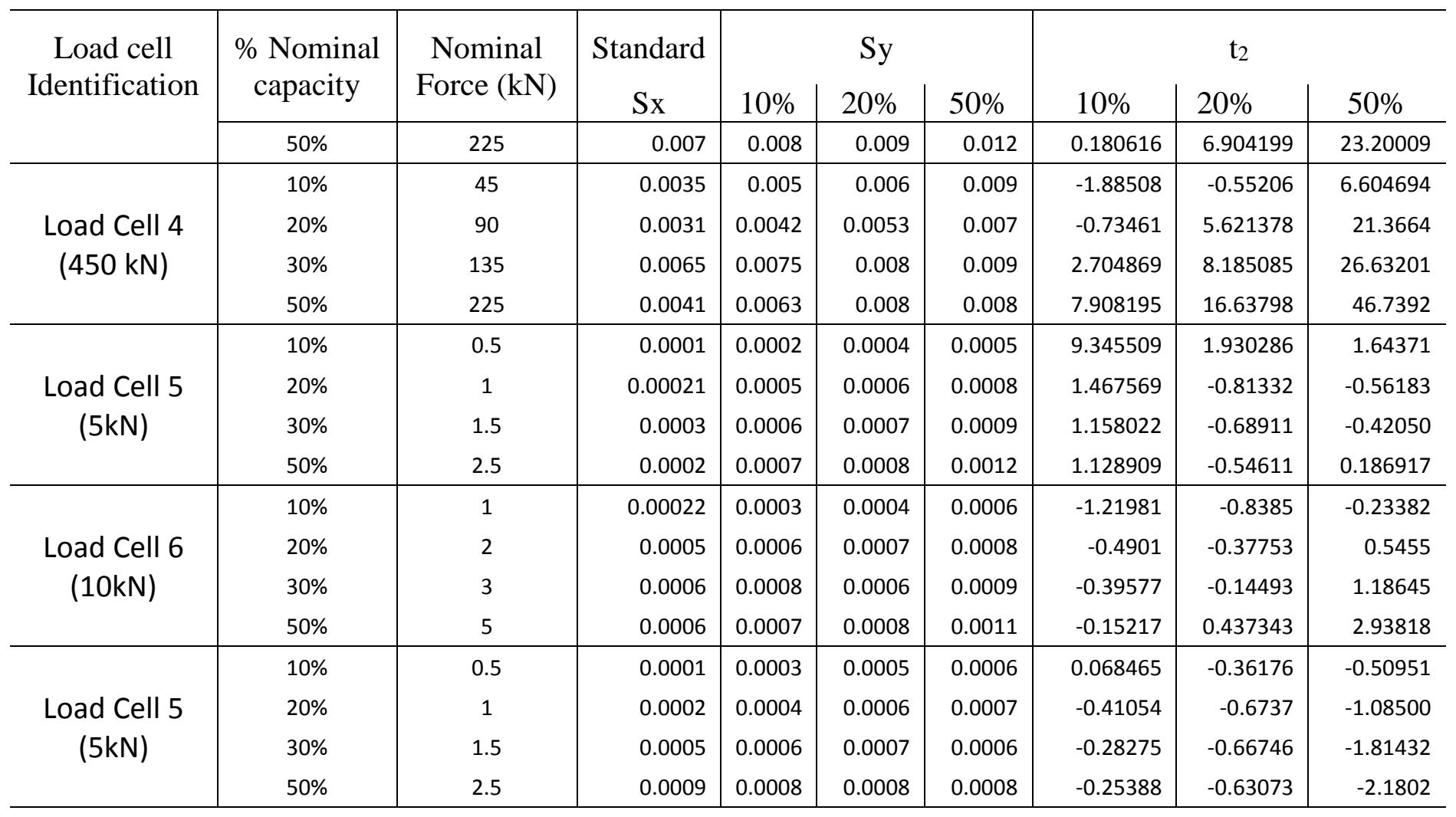

\section{REFERENCES}

[1] Dan Mihai Stefanescu, Alexandru Stefanescu. "Criteria for Choosing the Elastic Elements of Force Transducers" In Proceedings of the 17th International conference IMEKO TC3. (Sept.2001).

[2] International Standard ASTM E74-16 "Standard Practice of calibration of force-measuring instruments for verifying the force indication of testing machines", 2016

[3] International Standard ISO376:2011 "Metallic materials - Calibration of force-proving instruments used for the verification of uniaxial testing machines" Fourth edition, June 2011.

[4] Morehouse universal loading frame operating manual- www.mhforce.com

[5] Shigley’s Mechanical Engineering Design," Mechanical engineering”, McGraw-Hill, Eights edition 2006, ISBN:0390-76487-6.

[6] DMP-40 catalogue, HBM Company-www.hbm.com.

[7] Charles Lipson "statistical Design and analysis of engineering experiments", Mc Graw-Hill,1985. 